Focused on Crack Tip Fields

\title{
Approximation of the crack-tip field in fatigue cracks in bridge steel specimens: DIC analysis of different constraint levels
}

\author{
S. Seitl, P. Miarka \\ Academy of Sciences of the Czech Republic, Institute of Physics of Materials, v. v. i., Zǐ̌kova 22, 61662 Brno, Czech Republic \\ and Brno University of Technology, Faculty of Civil Engineering, Institute of Structural Mechanics, Veveri 331/95, 60200 Brno, \\ Czech Republic
}

seitl@ipm.cz, http:/ / orcid.org/0000-0002-4953-4324

Petr.miarka@vut.cz.bttp://orcid.org/0000-0002-4953-4324

V. Růžička, L. Malíková,

Brno University of Technology, Faculty of Civil Engineering, Institute of Structural Mechanics, Veveřz 331/95, 60200 Brno, Czech Republic

rusicka@musicer.net, bttps://orcid.org/0000-0002-1954-6340

malikova.l@fce.vutbr.cz,bttp://orcid.org/0000-0001-5868-5717

\author{
A. S. Cruces, P. Lopez-Crespo \\ Department of Civil and Materials Engineering, University of Malaga, C/Dr Ortiz Ramos s/n, 29071 Malaga, Spain \\ ascruces@uma.es \\ plopezcrespo@uma.es, https://orcid.org/0000-0002-5897-5615
}

\begin{abstract}
A study on the accuracy of the approximation of the displacement field around of crack tip in a sample made from bridge steel (S355) is main objective of contribution. Linear elastic fracture mechanics (LEFM) theory in framework of multi-parameter formulation, i.e. postulated by Williams is used to determine of coefficients of Williams power series terms. Over deterministic method was used to calculate the terms based on the least squares regression technique, applied on data from numerical simulation and experiment on S355 steel grades. Comparison between the stress fields (by principal stress $\sigma_{1}$ and von Mises stress $\sigma_{\mathrm{HMH}}$ ) obtain from experimental measurement DIC, Hybrid method and obtain from reconstruction by using various number of Williams power terms are quantified in order to get key information around the crack tip region on bridge steel specimens.
\end{abstract}

KEYWORDS. Displacement; Crack-tip stress fields; DIC; High order terms; Multi-parameter approximation accuracy; Williams power series.

\section{OPEN ACCESS}

Citation: Seitl, S., Miarka, P., Ruzicka, V., Malikova, L., Cruces, AS. Lopez-Crespo, P. Approximation of the crack-tip field in fatigue cracks in bridge steel specimens: DIC analysis of different constraint levels, Frattura ed Integrità Strutturale, 49 (2019) 97-106.

Received: 16.05 .2019 Accepted: 22.05.2019 Published: 01.07.2019

Copyright: (C) 2019 This is an open access article under the terms of the CC-BY 4.0, which permits unrestricted use, distribution, and reproduction in any medium, provided the original author and source are credited. 


\section{INTRODUCTION}

$\mathrm{N}$

on-destructive inspections of fatigue loaded components or civil engineering structures are usually performed to predict the size and the locations of cracks that are created from singular stress concentrator/defects during the manufacturing process or service life. The existence of cracks changes predictable load-bearing capacity and service interval [1-4] of the civil engineering components especially during the fatigue loading.

Characterisation of stress fields near crack tip has been studied for many decades; see for example a short state-of-art [5] where an Over Deterministic Method (ODM) is presented to evaluate the combination of mode I and mode II by using photo-elasticity for drawing isoline and given number of WE terms [6]. The ODM has also been employed successfully to analyse bulk strain data obtained with synchrotron tests [7,8]. Understanding the evolution of higher order terms for different geometries is key to predict the constraint of elastic-plastic crack tip fields [9]. Consequently, a large effort has been devoted in recent times to develop algorithms for fast determination of higher order terms and to improve the accuracy in the estimation of higher order terms [10-13] both quasi-statically [14] and in dynamic situations [15].

Digital Image Correlation technique (DIC) was applied successfully on NiTi pseudoelastic alloy for evaluation of fracture toughness and another fracture properties [16]. In the papers [17, 18, 23-27], the displacement field in the surrounding of a crack tip of single edge geometry specimens was employed in conjunction with Williams power series to estimate the stress intensity factor (SIF). The higher-order terms effects were analysed by using Williams expansion (focusing of T-stress) for various sizes of the crack tip distance of applied region for fitting data. A comparison between the SIF results and the analytical solution was established.

The aim of this contribution is to analyse the various stress fields in the vicinity of the crack tip that were constructed from the data obtained from measurement of the displacement field by DIC by comparing the crack tip field approximations obtained with the ODM [28] and hybrid element method [29, 30].

The displacement field in the vicinity of the crack tip, which is necessary for the following analysis, was measured in a standard compact tension (CT-[31]) specimen made of S355 J2 under the constant value of stress intensity factor $\Delta K_{\mathrm{I}}=15$ MPa $\sqrt{m}_{\mathrm{m}}$.(according ASTM E647, [32]). The linear elastic fracture mechanics (LEFM, [38]) theory was applied on calculation of displacement vector components to be more precisely the multi-parameter formulation given by Williams [39] is applied. Calculation of terms coefficients of Williams power series was applied the least squares-based regression technique marked ODM, [28] for which displacements data obtained experimentally from optical measurements are taken as inputs.

The influence of the number of terms considered for the power series reconstruction of two kinds of definition for the stress fields for the calculation of the values of coefficients of those terms are investigated in the current paper.

\begin{tabular}{ccccccccc}
\hline Steel & $\begin{array}{c}\mathrm{C} \\
(\max . \%)\end{array}$ & $\begin{array}{c}\mathrm{Mn} \\
(\max . \%)\end{array}$ & $\begin{array}{c}\mathrm{Si} \\
(\max \%)\end{array}$ & $\begin{array}{c}\mathrm{P} \\
(\max \%)\end{array}$ & $\begin{array}{c}\mathrm{S} \\
(\max . \%)\end{array}$ & $\begin{array}{c}\mathrm{N} \\
(\max . \%)\end{array}$ & $\begin{array}{c}\mathrm{Cu} \\
(\max . \%)\end{array}$ & $\begin{array}{c}\mathrm{CEV} \\
(\max . \%)\end{array}$ \\
$\mathrm{S} 355 \mathrm{~J} 2$ & 0.2 & 1.6 & 0.55 & 0.03 & 0.03 & - & 0.55 & 0.47 \\
\hline
\end{tabular}

Table 1: Chemical composition in percentage by weight (wt. \%) of the used steel grades according to EN 10025-2:2004 standard.

\begin{tabular}{ccccc}
\hline Young's modulus & Yield stress & UTS & Elongation at break & Poisson's ratio \\
$205.4 \pm 7.4 \mathrm{GPa}$ & $381.94 \pm 6.22 \mathrm{MPa}$ & $554.41 \pm 1.62 \mathrm{MPa}$ & $34.22 \pm 1.54 \%$ & $0.3[1]$ \\
\hline
\end{tabular}

Table 2: Mechanical properties of S355 J2 mean values with standard deviation.

\section{EXPERIMENTAL STUDY}

\section{Material S355 22 and method of measurement}

7 he experiments were conducted on a Compact Tension (CT) geometry that were machined in the T-L direction that is the rolling direction was parallel to the crack growing direction. The specimen was machined according to ASTM E647 [32].

The material was S355 J2 structural steel that is commonly used offshore, marine and structural applications. The chemical composition of the steel grade is specified in EN 10025-2:2004 standard and is presented in [33]. Chemical composition of the experimental material was verified by producer, and it is in agreement with the standard presented in this paper and measured mechanical properties of the $\mathrm{S} 355 \mathrm{~J} 2$ are summarized in Tab. 2, the fatigue properties were published e.g. [34-37]. 
The tested CT specimens had dimensions: $L=62.5 \mathrm{~mm}, W=50 \mathrm{~mm}, B=10 \mathrm{~mm}, a_{\mathrm{n}}=12.5 \mathrm{~mm}, H / 2=30 \mathrm{~mm}$ and the angle $\beta_{1}=60^{\circ}$, Fig. 1 .

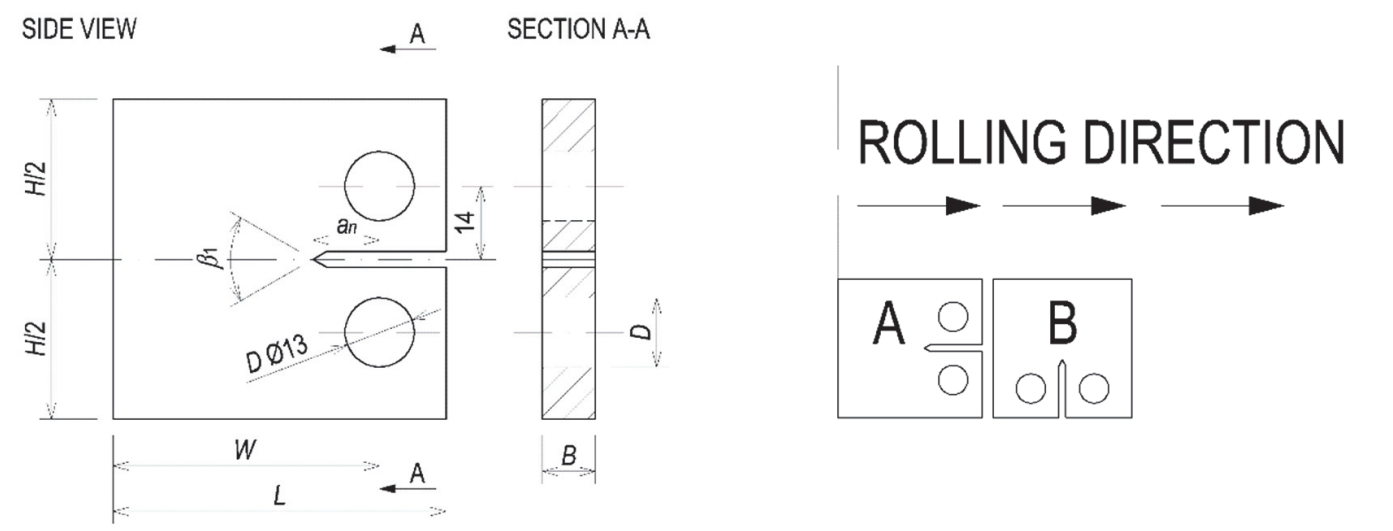

Figure 1: Schematic of the compact tension (CT) specimen employed, including the dimensions. ASTM E647 [32] was followed in the machining of the specimen. The rolling direction is also shown in the figure.

Specimens were prepared from a metal sheet in two different orientations to the sheet rolling direction. Specimens were marked with letters "A-crack propagating along rolling direction" and "B-crack propagating across to rolling direction" to see the influence of the material structure orientation on the crack propagation rate. In case of the specimens marked with letter "A", the initial crack (notch) is oriented parallel to rolling direction, whereas with letter " $B$ " the initial crack (notch) is oriented perpendicular to the rolling direction (rotated by $90^{\circ}$ ), the microstructure of S355 J2 for different rolling direction is shown in Fig. 2.

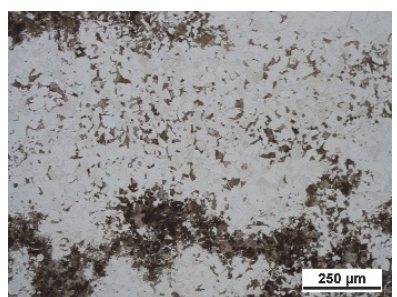

a) $\mathrm{S} 355 \mathrm{~J} 2 \mathrm{~A}$

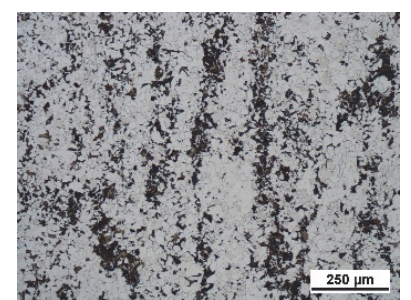

b) S355 J2B

Figure 2: Figure Structure of the S355 J2 steel grade, the crack was propagating in the horizontal direction; etched with 2\% Nital, light optical microscope

\begin{tabular}{ccccccccc}
\hline$a / W$ & 0.310 & 0.350 & 0.390 & 0.450 & 0.490 & 0.650 & 0.690 & 0.750 \\
$P_{\max }$ & 6.490 & 5.860 & 5.280 & 4.490 & 4.000 & 2.220 & 1.830 & 1.300 \\
$P_{\min }$ & 0.649 & 0.586 & 0.528 & 0.449 & 0.400 & 0.222 & 0.183 & 0.130 \\
$\Delta P$ & 5.841 & 5.274 & 4.752 & 4.041 & 3.600 & 1.998 & 1.647 & 1.170 \\
\hline
\end{tabular}

Table 3: Examples of forces values $\left(P_{\max }, P_{\min }\right.$ and $\left.\Delta P\right)$ versus relative crack length $(a / W)$ applied for CT specimen for constant range of stress intensity factor $\Delta K_{\mathrm{I}}=15 \mathrm{MPa} V_{\mathrm{m}}$ according ASTM E647 [32].

The fatigue propagation test was conducted on a $100 \mathrm{kN}$ Instron sevo-hydraulic rig. The precracking was implemented for 120,000 cycles, a frequency of $20 \mathrm{~Hz}$ and a load ratio, $\mathrm{R}$, of 0.1 . Attention was paid throughout the test to fulfil small scale yielding conditions (see the paragraph entitled Justification of using LEFM). The value of stress intensity has changed each $1 \mathrm{~mm}$ of crack growing to be at given point $15 \mathrm{MPam}^{1 / 2}$. The selected values of forces for relative crack length, calculated for given range of $\Delta K$ according ASTM E647 [32], are mentioned in Tab. 3. 
Justification of using LEFM

Condition of small scale yielding is a very useful concept [38], which has been used to describe that the linear extension of the plastic region is small compared to significant dimensions of the body, particularly the crack length

$$
a \geq 2.5\left(\frac{K_{I}}{\sigma_{Y}}\right)^{2}
$$

Due to the high gradient that takes place at the crack tip because of the crack tip singularity, a certain plastic deformation will occur. The extension of this plastic deformation was estimated with Irwin's model where the plastic radius can be inferred along the $\mathrm{x}$-axis, by equating the stresses acting on the crack opening direction to the yield stress of the material:

$$
\begin{aligned}
& r_{p}=\frac{1}{2}\left(\frac{K_{I}}{\sigma_{Y}}\right)^{2}-\text { plane stress, } \\
& r_{p}=\frac{1}{6}\left(\frac{K_{I}}{\sigma_{Y}}\right)^{2}-\text { plane strain. }
\end{aligned}
$$

In Eqns. 2 and 3, $K_{\mathrm{I}}$ is stress intensity factor and $\sigma_{\mathrm{y}}$ is yield stress. Therefore, valid points from used DIC measurement were taken in higher distance than $0.25 \mathrm{~mm}$.

\section{Full-field experimental measurement of displacements}

Key experimental information of the displacement field around the crack tip was obtained with Digital Image Correlation (DIC). The study was conducted for various crack lengths and one load level (see Tab. 3). DIC is a powerful full-field technique that enables the in-plane displacement field between two different strain states to be measured. DIC technique works by splitting the image of the analysed surface into a small squared images also called interrogation windows. It is based on the cross-correlation function [40] that evaluates the similarity between the different interrogation windows during the different strain states:

$$
c(u, v)=\sum_{x=-\frac{N}{2}}^{x=\frac{N}{2}} \sum_{y=-\frac{N}{2}}^{y=\frac{N}{2}} I_{A}(x, y) \cdot I_{B}(x+u, y+v),
$$

where $c$ is the cross-correlation function that depends on the horizontal, $u$, and vertical, $v$, displacement vectors that join the centre of all interrogation windows in the two different strain states. $I_{A}$ and $I_{B}$ are distributions of the intensity across the two images captured in the two different strain states. $N$ is the total number of interrogation windows included in each image. The maximum of the cross-correlation function indicates the most likely displacement vector for all the interrogation windows.

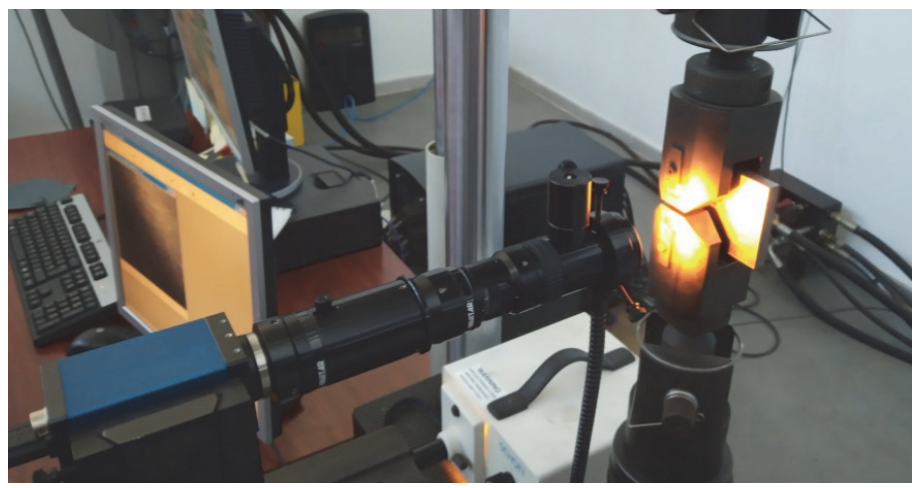

Figure 3: Set up for fatigue measurement with digital image correlation (DIC) 
The experimental setup is shown in Fig. 3. Fig. 3 shows the loading fixture employed to apply mode I loading on the CT geometry and the DIC experimental system. This includes the digital camera, the macro-lens and fibre-optics co-axial illumination. The camera was positioned so that the crack propagation direction was parallel to the positive $x$ coordinate. The crack opening direction was parallel to the y coordinate [17]. Such pre-arranging simplifies the post-processing of the results [18], in particular for non pure mode I cracks (i.e. for mixed mode cracks, e.g. [19, 20]. Unlike most previous works where speckle pattern was obtained by spraying the surface with black and white paint [21,22], here we obtain a random pattern in the studied surface by abrading the surface with different grades $\mathrm{SiC}$ papers [23, 24]. Such procedure yielded excellent results in the past with similar types of alloys [25]. Moreover, the recommendations generated in previous studies were incorporated in the tests [26]. The digital images were acquired with a $2452 \times 2052$ pixels CCD camera with 8 -bit dynamic range. The frame rate of the camera was set to 12 . Overall the camera/sample/illumination/loading rig setup was analogous to that employed previously [10, 27]. In order to not introduce additional sources of error, the raw information measured by DIC, was fed into the elastic analytical model to conduct the fracture mechanics analysis (see following section). That is, horizontal, $u$, and vertical, $v$, displacement information was used, rather than strain information that requires an additional step.

\section{THEORETICAL BACKGROUND: MULTI-PARAMETER FRACTURE MECHANICS}

Stress and displacement field near crack tip for mode I

7 he stress and displacement distribution near crack tip can be written by a power series that was introduced by Williams in [39]. In a homogeneous linear-elastic isotropic material (described by $E$ - Young modulus and $v-$ Poisson ratio), for the crack loaded by mode I loading, the stress field/displacement field around the crack tip can be expressed by following Williams eigenfunction expansion:

$$
\left\{\begin{array}{l}
\sigma_{x} \\
\sigma_{y} \\
\tau_{x y}
\end{array}\right\}=\sum_{n=1}^{\infty} \frac{n}{2} r^{\frac{n}{2}-1} A_{n} \cdot\left\{\begin{array}{l}
{\left[2+(-1)^{n}+\frac{n}{2}\right] \cos \left(\frac{n}{2}-1\right) \theta-\left(\frac{n}{2}-1\right) \cos \left(\frac{n}{2}-3\right) \theta} \\
{\left[2-(-1)^{n}-\frac{n}{2}\right] \cos \left(\frac{n}{2}-1\right) \theta+\left(\frac{n}{2}-1\right) \cos \left(\frac{n}{2}-3\right) \theta} \\
-\left[(-1)^{n}+\frac{n}{2}\right] \sin \left(\frac{n}{2}-1\right) \theta+\left(\frac{n}{2}-1\right) \sin \left(\frac{n}{2}-3\right) \theta
\end{array}\right\} .
$$

Similarly, the displacement vector can be written as:

$$
\left\{\begin{array}{l}
u \\
v
\end{array}\right\}=\sum_{n=1}^{\infty} \frac{r^{n / 2}}{2 \mu} A_{n} \cdot\left\{\begin{array}{l}
\left(\kappa+\frac{n}{2}+(-1)^{n}\right) \cos \frac{n}{2} \theta-\frac{n}{2} \cos \left(\frac{n}{2}-2\right) \theta \\
\left(\kappa-\frac{n}{2}-(-1)^{n}\right) \sin \frac{n}{2} \theta+\frac{n}{2} \sin \left(\frac{n}{2}-2\right) \theta
\end{array}\right\} .
$$

In Eqns. 5 and 6, $r$ and $\theta$ are polar coordinates with the start of coordinate system in the crack tip), $\mu$ is shear modulus defined as $\mu=E / 2(1+v)$, where $n$ denotes the index of the term in the series development and $\kappa$ is the Kolosov constant defined for plane stress $((3-v) /(1+v))$ or plane strain (3-4v) conditions. Coefficients of WE marked $A_{n}$ depend on relative crack length $\alpha=a / W$. The start of polar coordinate system was positioned at the crack tip [40] and curvature of crack was not considered [41]. It is good to mention, that bulk effect was not taken in account like in [42]. The used shortened form of the WPS used $N$ terms is applied on description of approximation of stress/displacement fields. When the crack is loaded by mixed-mode [44], Eqns. 5 and 6 have to include a shear mode terms, see e.g. [45, 46].

\section{Over-deterministic method (ODM)}

In the scientific literature [29, 30, 47, 48], various numerical procedures for calculation of the coefficients of the Williams power series can be found. Some of them are based on the hybrid crack elements, boundary collocations or other mathematically more difficult definitions and techniques. Contrary to that, there exist a relatively simple method that can utilize the basic results of data postprocessing included in each commercial finite element software. The method is called 
over-deterministic (ODM) [28], because the coefficients are obtained from an over-determined system of equation. These equations are formed based on Eqn. 6. The principle consists in choosing a set of particular nodes around the crack tip. The number of nodes, $k$, corresponds to the number of Williams expansion terms, $N$, that should be determined (it has to hold that $2 \mathrm{k} \geq N+1$ for mode I configurations). The displacements of these nodes obtained experimentally from the DIC measurements are used as inputs for Eqn. 6 together with their polar coordinates (the total number of nodes between the radius from 0.25 up $1 \mathrm{~mm}$ around the crack tip was approximately 120 for each configuration). Thus, the coefficients $A_{n}$ could be calculated, which was programmed in Wolfram Mathematica code [49] and php software [50]. More details on advantages, restrictions and accuracy of the ODM can be found in [10-13].

\section{Methods of Reconstruction of stress fields in vicinity of a crack tip}

The knowledge of higher-order terms of the WE from Eqn. 5 allow us to plot the stress isolines for given values of stress. In the contribution, two methods of approximation are used: the principal stress $\sigma_{1}$ and von Mises stress $\sigma_{\mathrm{HMH}}$. The following equations show how to calculate these stress values:

$$
\begin{aligned}
& \sigma_{1}=\frac{\sigma_{x}+\sigma_{y}}{2}+\sqrt{\left(\frac{\sigma_{x}-\sigma_{y}}{2}\right)^{2}+\tau_{x y}^{2}} \\
& \sigma_{\mathrm{HMH}}=\sqrt{\sigma_{x}^{2}-\sigma_{x} \sigma_{y}+\sigma_{y}^{2}+3 \tau_{x y}^{2}}
\end{aligned}
$$

where $\sigma_{\mathrm{x}}, \sigma_{\mathrm{y}}$ are normal stress components in $x$ and $y$ direction and $\tau_{\mathrm{xy}}$ is shear stress component. For comparison of stress distribution around the crack tip, the coefficients of the WE obtain via the hybrid crack elements for a normalized CT specimen were taken from the literature [29].

\section{RESULTS AND DISCUSSION}

Stress intensity factor (SIF)

IF values obtain from various methods were compared, see Tab. 4. The suggested values $15 \mathrm{MPam}^{1 / 2}$ obtained according ASTM E647 [32] CT fatigue tests (see Tab. 3) are compared to SIF values obtain by using combination of

\begin{tabular}{|c|c|c|c|c|c|c|c|}
\hline $\begin{array}{c}a \\
{[\mathrm{~mm}]}\end{array}$ & $\begin{array}{c}a / W \\
{[1]}\end{array}$ & $\begin{array}{c}\Delta P \\
{[\mathrm{kN}]}\end{array}$ & $\begin{array}{c}\text { Fracture test } \\
\Delta K \\
{\left[\mathrm{MPa} \mathrm{m}^{1 / 2}\right]}\end{array}$ & $\begin{array}{c}\text { Optical } \\
\text { measurements } \\
\text { (DIC) } \\
\Delta K \\
{\left[\mathrm{MPa} \mathrm{m}^{1 / 2}\right]}\end{array}$ & $\begin{array}{c}\text { Optical } \\
\text { measurements } \\
\text { (DIC) } \\
\text { T-stress } \\
\text { [MPa] }\end{array}$ & $\begin{array}{c}\text { Knésl \& } \\
\text { Bednáŕ [29] } \\
\Delta K \\
{\left[\mathrm{MPa} \mathrm{m}^{1 / 2}\right]}\end{array}$ & $\begin{array}{c}\text { Knésl \& } \\
\text { Bednáŕ [29] } \\
\text { T-stress } \\
{[\mathrm{MPa}]}\end{array}$ \\
\hline 16 & 0.32 & 5.70 & 15 & 15.05 & 19.34 & 15.01 & 20.07 \\
\hline 26 & 0.52 & 3.28 & 15 & 14.82 & 25.23 & 14.93 & 28.71 \\
\hline 35 & 0.70 & 1.56 & 15 & 15.01 & 26.02 & 14.96 & 26.24 \\
\hline 43 & 0.86 & 0.47 & 15 & 15.03 & 40.36 & 15.02 & 45.12 \\
\hline
\end{tabular}
DIC and ODM methods and SIF values obtained by using the hybrid crack elements like Knésl \& Bednár in [29].

Table 4: Values of the stress intensity factors (SIFs) in MPa $\sqrt{m}$ and $\mathrm{T}$-stress MPa for selected crack length obtained: from fracture tests ASTM E647, [32], combination of DIC and ODM methods and SIF values obtained by using the hybrid crack elements like Knésl \& Bednár in [29].

\section{T-stress for CT specimen}

Fig. 4 shows the value of $\mathrm{T}$-stress versus $a / W$ for CT specimen in case of static load $K_{\mathrm{I}}=15 \mathrm{MPa} \mathrm{m} \mathrm{m}^{1 / 2}$. Therefore, the presented results are for selected relative crack lengths $a / W$ where level of constraint (T-stress) is different, see Tab. 3. 
Comparison of stress fields in vicinity of a crack tip

For comparison of experimentally obtain data and numerically calculated, the relative crack length 0.86 were selected due to maximal value of constraint (T-stress), see Tab. 3 and Fig. 4. In Fig. 5, $\sigma_{1}$ and $\sigma_{\mathrm{HMH}}$ the approximation of the crack tip stresses taking into account one and two terms of the Williams power series on specimen are shown: a) stress values calculated from the coefficients determined theoretically [29]; b) stress values computed from the coefficients that were calculated through the ODM from the experimental displacement information.

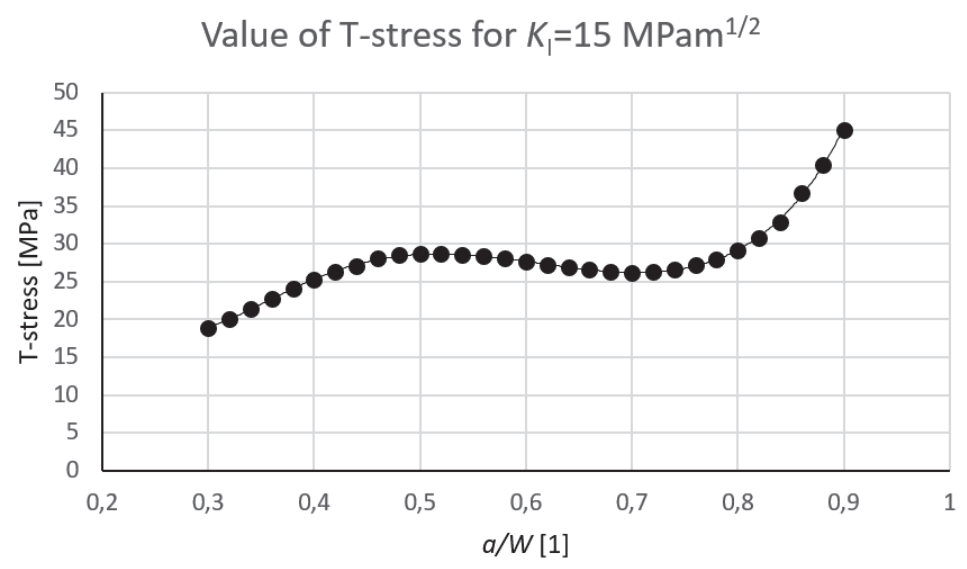

Figure 4: Value of T-stress versus relative crack length $a / W$ for CT specimen in case of static load $K_{\mathrm{I}}=15 \mathrm{MPa} \mathrm{m}^{1 / 2}$.
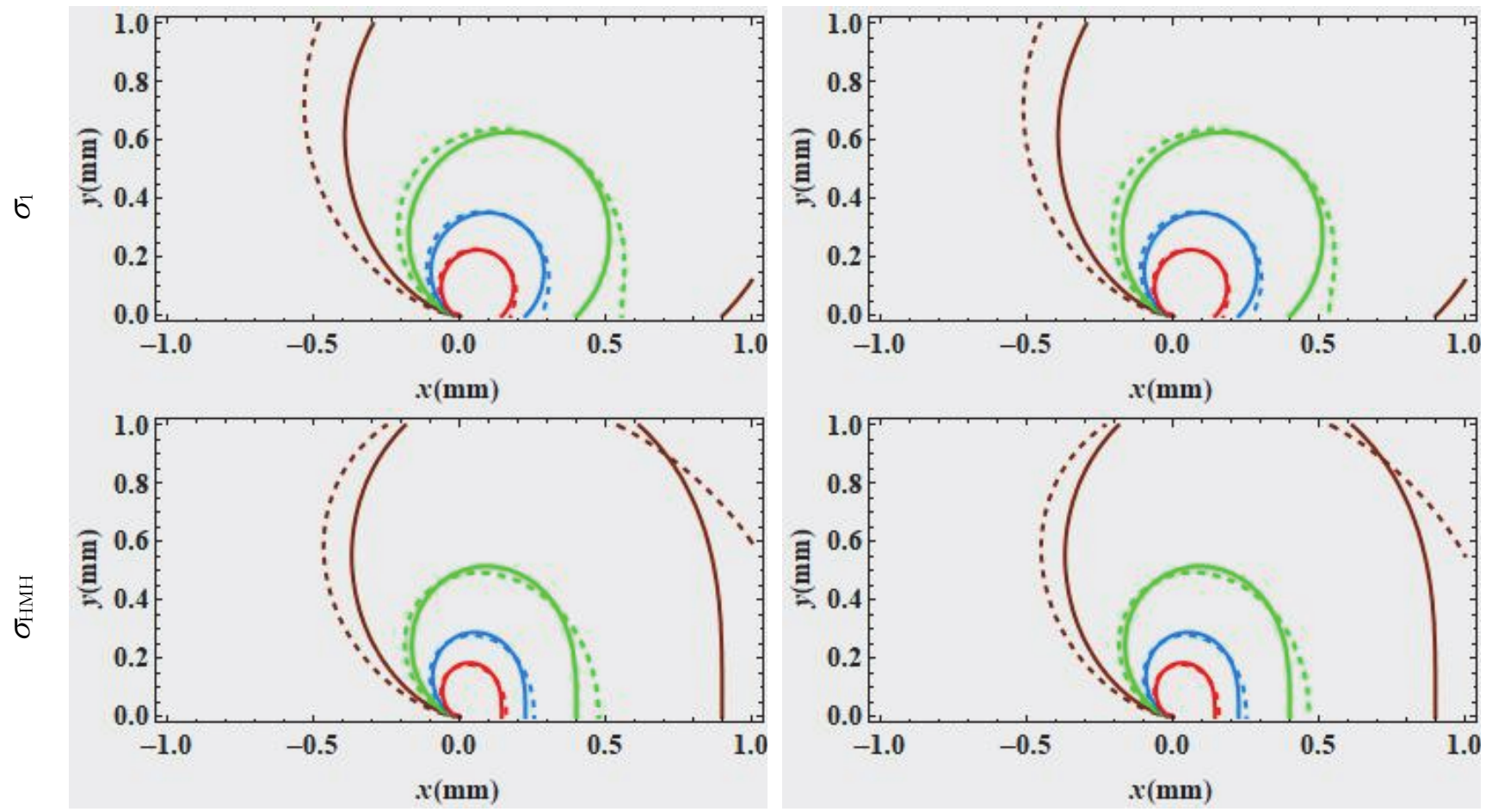

a) Knésl \& Bednář [29]

b) $\mathrm{DIC}+\mathrm{ODM}$

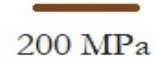

$300 \mathrm{MPa}$

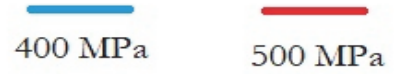

Figure 5: $\sigma_{1}$ and $\sigma_{\mathrm{HMH}}$ crack tip stress approximation considering one (thick lines) and two (dashed lines) initial terms of the Williams expansion on specimen with the relative crack length 0.86: a) isoline of stresses calculated from the coefficients determined theoretically [29]; b) isoline of stresses calculated from the coefficients calculated by ODM from the DIC measurements. 


\section{CONCLUSION}

$\mathrm{T}$ his work presents an investigation regarding the stress distribution around a fatigue crack tip. The study has been conducted on a S355 steel often used in offshore, marine and structural applications. The experimental program is based on CT specimens analysed by means of DIC full-field technique. Different cases with constant stress intensity factor, $\Delta K=15 \mathrm{MPam}^{1 / 2}$, were analysed. One of the main outputs has been inferring the Fourier coefficients that are required to approximate the Williams expansion describing the field. This has allowed the crack tip stress field distribution for be reconstructed for a real fatigue crack. The results have been validated by comparison between the Williams based analysis and theoretical solutions. The current research is part of a broader investigation program aimed at multi-parameter characterisation of failure in metals.

\section{ACKNOWLEDGEMENTS}

$\mathrm{F}$ inancial support from the Czech Science Foundation (project No. 17-01589S), and from Ministerio de Economia y Competitividad through grant reference MAT2016-76951-C2-2-P is gratefully acknowledged. This paper has been worked out under the "National Sustainability Programme I" project "AdMaS UP - Advanced Materials, Structures and Technologies" (No. LO1408) supported by the Ministry of Education, Youth and Sports of the Czech Republic and Brno University of Technology.

\section{REFERENCES}

[1] Krejsa, M. Brozovsky, J. Lehner, P. Seitl, S. and Kala, Z. (2018) Stochastic analysis for short edge cracks under selected loads, AIP Conference Proceedings, 1978, art. no. 150006, DOI: 10.1063/1.5043797

[2] Lehner, P. Křivý, V. Krejsa, M. Pařenica, P. and Kozák, J (2018) Stochastic Service Life Prediction of Existing Steel Structure Loaded by Overhead Cranes, Procedia Structural Integrity, 13, pp. 1539-1544. DOI: 10.1016/j.prostr.2018.12.314

[3] Janas, P. Krejsa, M. Sejnoha, J. and Krejsa, V. (2017) DOProC-based reliability analysis of structures, Structural Engineering and Mechanics, 64(4), pp. 413-426. DOI: 10.12989/sem.2017.64.4.413

[4] Kala, Z. (2018) Probabilistic modelling of fatigue crack - Some observations about conditional probability, International Journal of Mechanics, 12, pp. 121-130.

[5] Stepanova, L. and Roslyakov, P. (2016) Multi-parameter description of the crack-tip stress field: Analytic determination of coefficients of crack-tip stress expansions in the vicinity of the crack tips of two finite cracks in an infinite plane medium, Int. J. Solids Struct., 100, pp. 11-28.

[6] Ramesh, K. Gupta, S.and Kelkar, A. A. (1997) Evaluation of stress field parameters in fracture mechanics by photoelasticity-Revisited, Eng. Fract. Mech., 56(1), pp. 25-45.

[7] Lopez-Crespo, P. Peralta, J.V. and Withers, P.J. (2018) Synchrotron X-ray diffraction based method for stress intensity factor evaluation in the bulk of materials. Theoretical and Applied Fracture Mechanics, 98, pp. 72-77.

[8] Lopez-Crespo, P. Peralta, J.V. and Withers, P.J. (2019) In situ through-thickness analysis of crack tip mechanics with synchrotron X-ray diffraction. International Journal of Fatigue, to appear. 2019.

[9] Sgambitterra, E. Lesci, S. and Maletta, C. (2015) Effects of Higher Order Terms in Fracture Mechanics of Shape Memory Alloys Bydigital Image Correlation, Procedia Eng., 109, pp. 457-464.

[10] Seitl, S. Malíková, L. Rủžička, V. Moreno, B. and Lopez-Crespo, P. (2018) Williams' expansion-based approximation of the displacement field in an $\mathrm{Al} 2024$ compact tension specimen reconstructed from optical measurements, Fatigue and Fracture of Engineering Materials and Structures, 41(10), pp. 2187-2196, DOI: 10.1111/ffe.12842

[11] Šestáková, L. (2013) How to enhance efficiency and accuracy of the over-deterministic method used for determination of the coefficients of the higher-order terms in Williams expansion," Appl. Mech. Mater., 245, pp. 120-125, DOI http://dx.doi.org/10.4028/www.scientific.net/AMM.245.120

[12] Šestáková, L. and Veselý, V. (2013) Convergence study on application of the over-deterministic method for determination of near-tip fields in a cracked plate loaded in mixed-mode," Appl. Mech. Mater., 249-250, pp. 76-81, DOI http://dx.doi.org/10.4028/www.scientific.net/AMM.249-250.76

[13] Růžička, V. Malíková, L. and Seitl, S. (2017) Over-deterministic method: The influence of rounding numbers on the accuracy of the values of williams' expansion terms, Frattura ed Integrita Strutturale, 11(42), pp. 128-135, DOI: 
10.3221/IGF-ESIS.42.14

[14] Mokhtarishirazabad, M. Lopez-Crespo, P. Moreno, B. Lopez-Moreno, A. and Zanganeh., M. (2017) Optical and analytical investigation of overloads in biaxial fatigue cracks. International Journal of Fatigue, 100(2), pp. 583-590.

[15] Mokhtarishirazabad, M. Lopez-Crespo, P. and Zanganeh, M. (2018) Stress intensity factor monitoring under cyclic loading by digital image correlation. Fatigue and Fracture of Engineering Materials and Structures, 41, pp. $2162-2171$.

[16] Clocksin, W. F. da Fonseca, J. Q. Withers, P. J.a nd Torr, P. H. S. (2002) Image processing issues in digital strain mapping, in Proceedings of SPIE, Application of Digital Image Processing XXV, 4790, pp. 384-395.

[17] Mokhtarishirazabad, M. Lopez-Crespo, P. Moreno, B. Lopez-Moreno, A. and Zanganeh, M. (2017) Optical and analytical investigation of overloads in biaxial fatigue cracks, Int. J. Fatigue, 100(2), pp. 583-590. DOI http:/ / dx.doi.org/10.1016/j.ijfatigue.2016.12.035

[18] Lopez-Crespo, P. Moreno, B. Lopez-Moreno, A and Zapatero, J. (2015) Study of crack orientation and fatigue life prediction in biaxial fatigue with critical plane models, Eng. Fract. Mech., 136, pp. 115-130.

[19] Lopez-Crespo, P. and Pommier, S. (2008) Numerical analysis of crack tip plasticity and history effects under mixed mode conditions, Journal of Solid Mechanics and Materials Engineering. 2, pp. 1567-1576.

[20] Lopez-Crespo, P. Burguete, R.L. Patterson, E.A. Shterenlikht, A. Withers, P.J. and Yates, J.R. (2009) Study of a crack at a fastener hole by digital image correlation, Experimental Mechanics. 49, pp. 551-559.

[21] Yoneyama, S. Ogawa, T. and Kobayashi, Y. (2007) Evaluating mixed-mode stress intensity factors from full-field displacement fields obtained by optical methods, Eng. Fract. Mech., 74, pp. 1399-1412.

[22] Lopez-Crespo, P. Moreno, B. Lopez-Moreno, A. and Zapatero, J. (2015) Characterisation of crack-tip fields in biaxial fatigue based on high-magnification image correlation and electro-spray technique, Int. J. Fatigue, 71, pp. 17-25.

[23] Lopez-Crespo, P. Burguete, R.L. Patterson, E.A. Shterenlikht, A. Withers, P.J. and Yates, J.R. (2009) Study of a crack at a fastener hole by digital image correlation, Exp. Mech., 49, pp. 551-559.

[24] Lopez-Crespo, P. Shterenlikht, A. Yates, J.R. Patterson, E.A. and Withers, P.J. (2009) Some experimental observations on crack closure and crack-tip plasticity, Fatigue Fract. Eng. Mater. Struct., 32, pp. 418-429.

[25] Lopez-Crespo, P. Moreno, B. Lopez-Moreno, A. and Zapatero, J. (2015) Characterisation of crack-tip fields in biaxial fatigue based on high-magnification image correlation and electro-spray technique," Int. J. Fatigue, 71, pp. 17-25.

[26] Mokhtarishirazabad, M. Lopez-Crespo, P. Moreno, B. Lopez-Moreno, A. and Zanganeh, M. (2016) Evaluation of crack-tip fields from DIC data: a parametric study, Int. J. Fatigue, 89, pp. 11-19.

[27] Lopez-Crespo, P. Garcia-Gonzalez, A. Moreno, B. Lopez-Moreno, A. and Zapatero, J. (2015) Some observations on short fatigue cracks under biaxial fatigue, Theor. Appl. Fract. Mech., 80, pp. 96-103.

[28] Ayatollahi, M. R. and Nejati, M. (2011) An over-deterministic method for calculation of coefficients of crack tip asymptotic field from finite element analysis, Fatigue Fract. Eng. Mater. Struct., 34(3), pp. 159-176.

[29] Knésl, Z. and Bednář, K. (1998) Two-parameter fracture mechanics: determination of parameters and their values (in Czech), IPM AS CR, v. v. i. Brno.

[30] Xiao, Q. Z. Karihaloo, B. L and Liu, X. Y. (2004) Direct determination of SIF and higher order terms of mixed mode cracks by a hybrid crack element, Int. J. Fract., 125(3), pp. 207-225.

[31] Farahani, B.V. Tavares, P.J. Belinha, J. and Moreira, P.M.G.P. (2018) Compact tension fracture specimen: Experimental and computational implementations on stress intensity factor, Journal of Strain Analysis for Engineering Design, 53(8), pp. 630-647. DOI: 10.1177/0309324718763189

[32] ASTM E647 (2005) Standard test method for measurement of fatigue crack growth rates.

[33] European Committee for Standardization (CEN) (2005) EN1993-1-9: Eurocode 3: Design of steel structures, part 19: Fatigue. Brussels. European Standard.

[34] Rozumek, D. Marciniak, Z. Lesiuk, G. and Correia, J. A. F. O. (2017) Mixed mode I/II/III fatigue crack growth in S355 steel, Procedia Structural Integrity, 5, pp. 896-903.

[35] de Jesus, A. M. P. Matos, R.B. Fontoura, .F.C. Rebelo, C. Simoes da Silva, L. and Veljkovic, M. (2012) A comparison of the fatigue behavior between S355 and S690 steel grades, Journal of Construction Steel Research, 79, pp. 140-150.

[36] Seitl, S. Miarka, P. Klusák, J. Fintová, S. and Kunz, L. (2018) Comparison of the Fatigue Crack Propagation Rates in S355 J0 and S355 J2 Steel Grades. In Local Mechanical Properties XIII. Key Engineering Materials (web). Trans Tech Publications, Switzerland, 784, pp. 91-96.

[37] Seitl, S. Miarka, P. Blasón, S. and Canteli, A. (2019) Evaluation of Fatigue Properties of S355 J2 and S355 J0 by Using ProFatigue Software, Book title: Mechanical Fatigue of Metals, Chapter 28.

[38] Anderson, T.L. (1995) Fracture Mechanics: Fundamentals and Applications. CRC Press. ISBN 978-0849316562

[39] Williams, M. L (1957) On the stress distribution at the base of a stationary crack," J. Appl. Mech., 24(1), pp. 109-114.

[40] Clocksin, W. F. da Fonseca, J. Q. Withers, P. J. and Torr, P. H. S. (2002) Image processing issues in digital strain 
mapping, in Proceedings of SPIE, Application of Digital Image Processing XXV, 4790, pp. 384-395.

[41] Zanganeh, M. Lopez-Crespo, P. Tai, Y.H. and Yates, J. R. (2013) Locating the crack tip using displacement field data: a comparative study, Strain, 49, pp. 102-115.

[42] Camas, D. Lopez-Crespo, P. Gonzalez-Herrera, A. and Moreno, B. (2017) Numerical and experimental study of the plastic zone in cracked specimens, Eng. Fract. Mech., 185, pp. 20-32, DOI http://dx.doi.org/10.1016/j.engfracmech.2017.02.016

[43] Lopez-Crespo, P. Mostafavi, M. Steuwer, A. Kelleher, J.F. Buslaps, T. and Withers, P. J. (2016) Characterisation of overloads in fatigue by 2D strain mapping at the surface and in the bulk, Fatigue Fract. Eng. Mater. Struct., 39(8), pp. 1040-1048.

[44] Lopez-Crespo, P. and Pommier, S (2008) Numerical analysis of crack tip plasticity and history effects under mixed mode conditions, J. Solid Mech. Mater. Eng., 2(12), pp. 1567-1576.

[45] Yoneyama, S Ogawa, T. and Kobayashi, Y. (2007) Evaluating mixed-mode stress intensity factors from full-field displacement fields obtained by optical methods,” Eng. Fract. Mech., 74, pp. 1399-1412.

[46] Lopez-Crespo, P. Shterenlikht, A. Patterson, E. A. Withers, P.J. and Yates, J. R. (2008) The stress intensity of mixed mode cracks determined by digital image correlation, J. Strain Anal. Eng. Des., 43, pp. 769-780.

[47] Tong, P. Pian, T. H. H. and Lasry, S. J. (1973) A hybrid-element approach to crack problems in plane elasticity," Int. J. Numer. Methods Eng., 7(3), pp. 297-308.

[48] Xiao, Q. Z. Karihaloo, B. L. Liu, X. Y. (2004) Direct determination of SIF and higher order terms of mixed mode cracks by a hybrid crack element, Int. J. Fract., 125(3), pp. 207-225.

[49] C. Wolfram Research, Inc., Ed., Wolfram Mathematica Documentation Center. 2007.

[50] http://php.net/software.php 